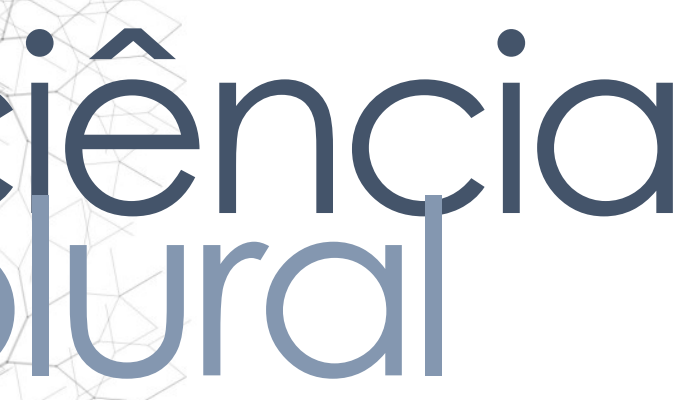

\title{
EXPERIÊNCIA DE ATUAÇÃO INTERPROFISSIONAL DO DENTISTA NA ESTRATÉGIA SAÚDE DA FAMÍLIA
}

Experience of interprofessional performance of dentist in Family Health Strategy

Experiencia de desempeño interprofesional del dentista en la Estrategia de Salud Familiar

Renan Cabral de Figueiredo - Mestre em Saúde da Família pelo Programa de Pósgraduação em Saúde da Família no Nordeste (RENASF/UFRN) •

E-mail: cabralrenan@yahoo.com.br

Ricardo Henrique Vieira de Melo • Mestre em Saúde da Família pelo Programa de Pós-graduação em Saúde da Família no Nordeste (RENASF/UFRN) • E-mail: ricardohvm@gmail.com

Maísa Paulino Rodrigues • Coordenadora do Mestrado Profissional em Saúde da Família no Nordeste (RENASF/UFRN) •

E-mail: maisarodrigues13@gmail.com

Georgia Costa de Araújo Souza - Professora Adjunta IV do Departamento de Odontologia da Universidade Estadual do Rio Grande do Norte (UERN) • E-mail: georgiacosta@uern.br

Rosana Lúcia Alves de Vilar • Professora Titular do Departamento de Enfermagem da Universidade Federal do Rio Grande do Norte (UFRN) •

E-mail: rosanaalvesrn@gmail.com

Autor responsável pela correspondência:

Renan Cabral de Figueiredo • E-mail: cabralrenan@yahoo.com.br 


\section{RESUMO}

Introdução: O acompanhamento do Crescimento e Desenvolvimento (CD) faz parte do escopo de ações desenvolvidas na Atenção Primária à Saúde e tem por propósito a saúde integral da criança. A atenção/assistência odontológica, iniciadas nos primeiros meses de vida, impacta positivamente sobre a saúde bucal e geral. Objetivo: O estudo objetivou compreender a perspectiva dos cirurgiões-dentistas no acompanhamento do crescimento e desenvolvimento infantil, no contexto da Estratégia Saúde da Família, em um município de médio porte. Metodologia: Trata-se de um estudo qualitativo, do tipo compreensivo-interpretativo, cujos participantes foram os dentistas atuantes no município referido. Os instrumentos de coleta foram: questionário semiestruturado, grupo focal e diário de campo. Os dados foram submetidos à análise temática de conteúdo. Resultados: Emergiram duas categorias: concepções sobre o CD; e ações desenvolvidas durante o CD. A saúde bucal aparece como potencialidade na atenção e assistência à saúde infantil, fortalecendo o processo de cuidar. Conclusões: Verificou-se o predomínio de percepções ancoradas em fundamentos que reduzem as dimensões subjetivas, culturais e sociais dos sujeitos, demonstrando distanciamento de uma prática interprofissional efetiva.

Palavras-Chave: Saúde Bucal. Crescimento e Desenvolvimento. Estratégia Saúde da Família.

\section{ABSTRACT}

Introduction: The monitoring of the Growth and Development (GD) is part of the scope of actions developed in primary health care and has the purpose of the integral health of the child. Dental care, initiated in the first months of life, positively impacts on oral and general health. Objective: The study aimed to understand the perspective of dentists in the monitoring of child growth and development, in the context of the Family health strategy, in a medium-sized city. Methodology: This is a qualitative study of the comprehensible-interpretative type, whose participants were the dentists working in the aforementioned city. The instruments of collection were: semistructured questionnaire, focal group and field diary. The data were subjected to thematic content analysis. Results: Two categories emerged: conceptions about the GD; and actions developed on the GD. Oral health appears as a potentiality in child health care and assistance, strengthening the care process. Conclusions: It was verified the predominance of perceptions anchored in fundamentals that reduce the subjective, cultural and social dimensions of the subjects, demonstrating distance of an effective interprofessional practice.

eywords: Oral Health. Growth and Development. Family Health Strategy.

\section{SUMEN}

roducción: El seguimiento del Crecimiento y el Desarrollo (CD) forma parte del ance de las acciones desarrolladas en la Atención Primaria de la Salud y tiene como jetivo la salud integral del niño. La atención / cuidado dental, iniciada en los imeros meses de vida, impacta positivamente la salud oral y general. Objetivo: El 
estudio tenía como objetivo entender la perspectiva de los dentistas en el seguimiento del crecimiento y desarrollo infantil, en el contexto de la Estrategia de Salud Familiar, en un municipio de tamaño mediano. Metodología: Se trata de un estudio cualitativo, de tipo de interpretación integral, cuyos participantes fueron dentistas que trabajaban en el municipio referido. Los instrumentos para la recogida fueron: cuestionario semiestructurado, grupo focal y diario de campo. Los datos fueron sometidos a análisis temáticos de contenido. Resultados: Surgieron dos categorías: concepciones sobre el CD; y las acciones desarrolladas en el CD. La salud bucal aparece como un potencial en la atención y el cuidado de la salud infantil, fortaleciendo el proceso de atención. Conclusiones: Se verifico el predominio de percepciones ancladas en fundamentos que reducen las dimensiones subjetivas, culturales y sociales de los sujetos, demostrando distanciamiento de una práctica interprofesional eficaz.

Palabras clave: Salud bucal. Crecimiento y Desarrollo. Estrategia de Salud Familiar. 


\section{Introdução}

A Atenção Primária à Saúde (APS) contempla um conjunto de ações de saúde individuais, familiares e coletivas, desenvolvida através de práticas de cuidado integrado, organizada pela Estratégia Saúde da Família (ESF), realizada com equipe multiprofissional e dirigida à população em territórios definidos¹.

As Equipes de Saúde Bucal (ESB), instituídas na ESF em 2000, são compostas por profissionais de Odontologia (dentista, auxiliar de saúde bucal e/ou técnico de saúde bucal) que, em parceria com os demais profissionais da APS (enfermeiro, médico, técnico de enfermagem, agente comunitário de saúde) favorecem a atuação das equipes multiprofissionais na $\mathrm{ESF}^{2}$.

Nessa direção, o fortalecimento da colaboração interprofissional entre as equipes de saúde possibilita maior efetividade das ações de acompanhamento do Crescimento e Desenvolvimento (CD) infantil. Assim, baseando-se no princípio da integralidade do cuidado, é pertinente discutir a contribuição do cirurgião-dentista, considerando suas especificidades enquanto categoria profissional, na promoção da saúde das crianças durante as consultas de $\mathrm{CD}^{3}$.

As diretrizes da Política Nacional de Saúde Bucal (PNSB), em 2004, propõem reorganizar as ações e serviços de saúde bucal em todos os níveis de atenção, apontando para o desenvolvimento de ações intersetoriais, com foco no cuidado à saúde e, também, ampliando concepções de saúde bucal que rompem com o paradigma biomédico (da assistência centrada em doenças bucais) adotando um novo modo de fazer e compreender o sujeito, a boca e suas subjetividades. Entre tais diretrizes, destaca-se o desenvolvimento de ações voltadas para a linha de cuidado infantil, buscando garantir o crescimento e o desenvolvimento adequados nos aspectos físico, emocional e social ${ }^{3}$.

A Política Nacional de Atenção Integral à Saúde da Criança (PNAISC), lançada 2015, orienta a promoção e a proteção da saúde da criança estimulando, também, leitamento materno, e reforça o compromisso do Estado brasileiro com a redução mortalidade infantil. O cuidado ao recém-nascido e a puérpera deve ser iniciado o precocemente possível, logo após o nascimento, durante a Primeira Semana de 
Saúde Integral (PSSI), que visa disponibilizar um cuidado mais integral e multiprofissional nas consultas de puericultura ${ }^{2,3}$.

A atenção e a assistência à saúde da criança geralmente são ofertadas de duas formas: através de consultas rotineiras de $C D$, realizadas de maneira partilhada e interprofissional; e por meio de atividades educativas e preventivas direcionadas as mulheres desde o início da gestação, sendo extensivas, também, aos pais e aos cuidadores das crianças. Essa combinação resulta na ampliação da compreensão sobre as vulnerabilidades infantis, pois se ancora em diversas áreas do conhecimento em saúde, buscando a integralidade do cuidado ${ }^{4}$.

Apesar dos investimentos e esforços para controlar a doença cárie na infância, este agravo ainda se constitui como um sério problema de saúde pública, mostrando uma prevalência de, aproximadamente, 53,4\% aos cinco anos de idade, o que demonstra a necessidade de intervenções e abordagens antecipadas, tanto no nível individual como no coletivo ${ }^{5}$. A atuação dos dentistas, junto aos pais e cuidadores, no intuito de desenvolver ações de prevenção e educação em saúde, pode contribuir significativamente para a redução de tal problemática ${ }^{6,7,8}$.

Portanto, é relevante averiguar, através de um recorte temporal, como vem ocorrendo a participação dos dentistas no acompanhamento do $C D$, no contexto da ESF, e se essa atividade tem sido desenvolvida enquanto uma prática uni, multi ou interprofissional. Este artigo, que apresenta parte dos resultados de uma dissertação realizada através do Programa de Pós-Graduação em Saúde da Família no Nordeste, teve como objetivo compreender a perspectiva dos cirurgiões-dentistas sobre o acompanhamento do crescimento e desenvolvimento infantil, no contexto da Estratégia Saúde da Família em um município de médio porte.

\section{Metodologia}

Trata-se de um estudo exploratório, qualitativo, desenvolvido em 19 Unidades sicas de Saúde (UBS) contempladas com ESF, no município de Caicó/RN, região tro-sul do estado, localizada a $256 \mathrm{~km}$ da capital, Natal, sendo o quinto município s extenso, com uma população estimada em 67.554 para o ano de 2018. 


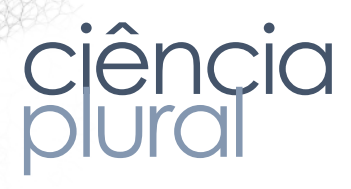

A amostra, por conveniência, foi composta pelo universo de cirurgiõesdentistas da ESF do município que, após duas recusas, resultou em um total de 18 participantes, convidados pelo pesquisador por meio de contato direto, momento em que tiveram a oportunidade de esclarecer dúvidas sobre os objetivos da pesquisa.

Para a coleta de dados, ocorrida entre fevereiro e abril de 2019, foram utilizados dois instrumentos, que permitiram a complementariedade dos achados: um questionário (aplicado por meio de entrevista, cujas principais perguntas foram: 1- $\mathrm{O}$ que você compreende por consulta de puericultura ou de CD?, 2- Na sua UBS são realizadas consultas de CD?,3- Que profissionais realizam esse tipo de consulta na sua UBS?, 4- Você participa ou já participou dessas consultas? Quantas vezes ou com que frequência participa?, 5- Se sim, quais ações você desenvolve?, 6- Você se sente seguro para realizar tais ações? Por quê?, 7- Na sua UBS, são realizadas atividades em saúde bucal para os bebês por outro profissional? O que você acha disso?, 8- O que você acha da participação do cirurgião-dentista nas consultas de puericultura? Justifique) e grupo focal (cujas perguntas geradoras foram: 1- O que vocês acham da consulta de CD compartilhada?, 2- Em que momento as atividades de saúde bucal para bebês devem ter início?, 3- Quais as facilidades e dificuldades em participar do CD?, 4- Qual a opinião de vocês sobre a socialização de conhecimentos sobre saúde bucal para os demais profissionais da equipe, para que eles possam, também, orientar os usuários durante o CD?, 5- Que tal pactuar algumas ações/condutas imprescindíveis para realizar durante o CD?), além de anotações complementares em diário de campo, onde foram escritos apontamentos pelo investigador, logo após cada encontro, sobre aspectos importantes percebidos no desenrolar do processo.

As entrevistas tiveram a duração média de quarenta minutos e ocorreram nas próprias Unidades de Saúde, em sala com privacidade e ambientação adequada, após as consultas de acompanhamento das crianças no programa CD, agendadas previamente conforme cronograma de atendimentos locais. Foi seguido um roteiro omposto por perguntas abertas que permitiam o surgimento de novas indagações, em como a caracterização do perfil dos participantes. 
Posteriormente, em outro momento, 11 dentistas participaram de um grupo focal, ocorrido nas dependências do Centro Regional de Referência em Saúde do Trabalhador (CEREST), em sala reservada e climatizada. As discussões foram mediadas pelo pesquisador e acompanhadas por um observador, a partir de um roteiro norteador, e ocorreram no tempo aproximado de 90 minutos. Todas as entrevistas e as discussões, no grupo focal, foram gravadas e transcritas, posteriormente.

A análise tomou como base o método de análise temática de conteúdo ${ }^{9}{ }^{10}$, que permitiu desvelar os núcleos de sentido que compõem uma comunicação, cuja presença ou frequência apresentem algum significado para o objeto da pesquisa. Dessa forma, a exploração do material possibilitou a compreensão do texto, e o acesso aos núcleos de sentidos com suas respectivas frequências, permitindo a identificação e classificação das categorias e subcategorias, buscando compreender a construção compartilhada que formou o senso comum desse grupo.

No intuito de preservar o anonimato dos participantes, as citações diretas foram nomeadas com a letra ' $\mathrm{D}$ ' (Dentista) seguida de um algarismo arábico (originadas do questionário) e de um algarismo romano (a partir do grupo focal), atribuídos de acordo com a ordem de transcrição. A pesquisa obteve prévia autorização do Comitê de Ética em Pesquisa (CEP) do Hospital Onofre Lopes (HUOL), da Universidade Federal do Rio Grande do Norte (UFRN), obtendo sua aprovação no parecer de $n^{\circ}$ 2.841.028.

\section{Resultados e Discussão}

Quanto ao perfil dos participantes, destaca-se que dez eram do sexo feminino e oito, masculino, com faixa etária variando entre 27 e 46 anos. Dois possuíam curso de mestrado, enquanto que 11 tinham especialização em saúde coletiva. A análise do material coletado gerou duas categorias temáticas, cada uma delas com três ubcategorias, conforme visualizado no quadro 1. 
Quadro 1: Categorias e subcategorias temáticas sobre a atuação do Cirurgião-Dentista no acompanhamento do Crescimento e Desenvolvimento. Caicó/RN. 2019.

\begin{tabular}{|c|c|c|}
\hline Categorias & Subcategorias & Unidades de Registro \\
\hline \multirow{2}{*}{$\begin{array}{c}\text { Concepções dos Dentistas } \\
\text { sobre o CD }\end{array}$} & Acompanhamento & 14 \\
\cline { 2 - 3 } & Prevenção/Promoção & 12 \\
\cline { 2 - 3 } & Direito de cidadania & 1 \\
\hline $\begin{array}{c}\text { Ações desenvolvidas pelos } \\
\text { Dentistas }\end{array}$ & $\begin{array}{c}\text { Procedimento Clínico } \\
\text { no CD }\end{array}$ & Odontológico \\
\cline { 2 - 3 } & Teste da Linguinha & 3 \\
\cline { 2 - 3 } & Educação em Saúde & 14 \\
\hline
\end{tabular}

Fonte: Dados da pesquisa. 2019.

A categoria 'concepções dos dentistas sobre o CD' (quadro 1) reuniu as concepções dos participantes acerca do crescimento e desenvolvimento infantil ressaltando o acompanhamento da criança; as ações de promoção da saúde e de prevenção de doenças; além de direito de cidadania. O quadro 2 detalha essas subcategorias. 
Quadro 2: Concepções dos dentistas sobre o acompanhamento do Crescimento e Desenvolvimento infantil. Caicó/RN. 2019.

\begin{tabular}{|c|l|}
\hline \multicolumn{1}{|c|}{ Subcategorias } & \multicolumn{1}{|c|}{ Núcleos de Sentido } \\
\hline Acompanhamento & $\begin{array}{l}\text { Referem que as crianças devem ser } \\
\text { acompanhadas de forma sistemática } \\
\text { durante os primeiros anos de vida. }\end{array}$ \\
\hline Prevenção/Promoção & $\begin{array}{l}\text { Descrevem conhecimentos e práticas de } \\
\text { promoção da saúde e prevenção de } \\
\text { doenças }\end{array}$ \\
\cline { 2 - 3 } & $\begin{array}{l}\text { Falam da importância de se realizar } \\
\text { ações educativas em saúde bucal junto } \\
\text { aos pais objetivando o empoderamento } \\
\text { para melhoria do cuidado da saúde } \\
\text { bucal das crianças }\end{array}$ \\
\hline Direito de Cidadania & $\begin{array}{l}\text { Compreende que o CD e a saúde bucal } \\
\text { são direitos de toda criança e que o } \\
\text { Estado deve garantir e assegurar esse } \\
\text { acesso. }\end{array}$ \\
\hline
\end{tabular}

Fonte: Dados da pesquisa. 2019.

A leitura do material revelou que a concepção dos dentistas, sobre a consulta de $\mathrm{CD}$, está fortemente relacionada a compreensão de acompanhamento sistemático das crianças, indicando a necessidade de se contar com a parceria e o empenho dos pais e/ou responsáveis nesse processo para que se possa obter resultados positivos sobre a saúde de crianças em tenra idade.

O acompanhamento sistemático das crianças permite a avaliação do estado nutricional, o desenvolvimento das habilidades e a detecção precoce de agravos que possam surgir nos primeiros anos de vida, inclusive na tomada de decisões para o esfecho necessário. Para corroborar com a percepção dos entrevistados, sobre a mpreensão de acompanhamento sobre o CD, pode-se observar sua importância vés do que postulam alguns autores ${ }^{11,12,13}$. 
Em estudo similar a este, Malaquias; Gaíva; Higarashi ${ }^{11}$ referem que a consulta da criança constitui um instrumento de acompanhamento, que para ser efetivo, fundamenta-se em consolidação do vínculo e empoderamento familiar quanto à pertinência desse cuidado. Em Cuba, as consultas de CD foram um dos maiores avanços do século XX reduzindo, significativamente, a morbimortalidade infantil.

Para Gaíva et al ${ }^{12}$, o crescimento e desenvolvimento das crianças se constitui como eixo norteador das ações básicas de saúde na infância. Gauterio, Irala e Cezar13 apontam que déficits de crescimento na infância estão associados à maior mortalidade, incidência de doenças infecciosas, prejuízo para o desenvolvimento psicomotor, diminuição do rendimento escolar e menor capacidade produtiva quando adulta. $\mathrm{O}$ Ministério da Saúde orienta a adesão ao acompanhamento do CD infantil, uma vez que este possibilita uma assistência integral por meio de ações preventivas que estimulam a detecção precoce de $\operatorname{agravos}^{14}$.

A 'prevenção/promoção' foi citada pelos entrevistados como quesito fundamental dentro de todo o processo do cuidar, isto é, revelaram que o momento das consultas de CD se constitui em espaço rico e primordial para a interlocução com os pais e para a efetivação e consolidação de vínculos. É através da prevenção que se pode evitar também as doenças gerais e bucais que afetam as crianças.

Esses resultados reforçam os achados de Ferreira et $\mathrm{al}^{15}$, ao afirmarem que as consultas de CD podem ser permeadas por ações educativas, que permitem a criação de vínculo e estímulo a participação familiar o que, provavelmente, irá contribuir para a promoção da saúde e prevenção de agravos às crianças em acompanhamento.

Como a cárie precoce na infância ainda apresenta alta prevalência e severidade, acometendo crianças nos primeiros anos de vida, o trabalho desenvolvido pelos dentistas no CD possui importância evidenciada ${ }^{8,16}$. Nessa perspectiva, Martins et al ${ }^{17}$ mostraram que intervenções educativas direcionadas às mães e cuidadores sobre spectos nutricionais, dietéticos, higiênicos, entre outros, relacionados a saúde bucal crianças, implicam em diminuição da doença cárie. Trabalhar sobre os aspectos da venção/promoção durante a infância é fundamental para auxiliar na aquisição de s hábitos de higiene e de alimentação saudável18. 
Essas intervenções devem ocorrer de forma integrada, isto é, junto com os demais profissionais de saúde da ESF, pois, como afirma Carnut ${ }^{19}$, a integralidade amplia o olhar dos profissionais para além da lógica da 'intervenção pura', buscando alcançar os contornos do que se compreende como 'cuidar', no âmbito da construção e produção da saúde dentro dos serviços.

Chama a atenção a fala de um dos entrevistados, que faz menção ao direito de cidadania, ao referir que a criança deve ser acompanhada e ter seu direito à saúde respeitado, conforme garante a constituição brasileira:

É o acompanhamento efetivo da criança em todos os seus aspectos: físico, mental e social garantindo assim um direito da população e a obrigação do Estado (D-7).

O profissional se reporta aos marcos legais que fundamentam o direito à cidadania no país, a saber, a Constituição Federal de 1988, que ao estabelecer novas normativas ético-políticas e jurídicas, enaltece o direito à vida e a saúde como prioridade absoluta ${ }^{20}$.

Nesse percurso histórico, a Lei orgânica da saúde deu início ao processo de regulamentação e funcionamento do SUS, defendendo, em seu artigo $2^{\circ}$, a saúde como direito fundamental do ser humano e dever do Estado devendo este, prover as condições para seu exercício. No mesmo ano, o Estatuto da Criança e do Adolescente (ECA) foi criado para garantir que a criança seja tratada como sujeito de direito pontuando, em seu artigo $7^{\circ}$, o direito a proteção à vida e à saúde e, no $\operatorname{artigo~} 11^{\circ}$, o acesso integral às linhas de cuidado voltadas à saúde da criança e do adolescente no SUS. Finalmente, no artigo $14^{\circ}$, enfatizou a promoção de programas de assistência médica e odontológica para a população infanti120.

Nessa direção, destaca-se, também, o papel fundamental da Portaria $\mathrm{n}^{\circ}$ 1.130/2015 que criou a Política Nacional de Atenção Integral à Saúde da Criança (PNAISC) cujo objetivo é a proteção infantil desde a gestação até os 9 anos de idade, meio de cuidados integrais e integrados que promovam condições de vida dignas queda nos índices de morbimortalidade ${ }^{20}$. 
A categoria 'ações desenvolvidas pelos dentistas durante o CD' traz as percepções dos profissionais no que tange a sua contribuição no processo de cuidar da criança, onde se extraiu três subcategorias que fazem referência ao teste da linguinha, as ações de educação em saúde e a realização dos procedimentos clínicoodontológicos, conforme visualizado no quadro 3.

Quadro 3: Ações desenvolvidas pelos dentistas durante o acompanhamento do Crescimento e Desenvolvimento. Caicó/RN. 2019.

\begin{tabular}{|c|l|}
\hline \multicolumn{1}{|c|}{ Subcategorias } & \multicolumn{1}{|c|}{ Núcleos de Sentido } \\
\hline Teste da Linguinha & $\begin{array}{l}\text { Referem à importância do exame da } \\
\text { base lingual para diagnóstico da } \\
\text { inserção do seu frênulo. }\end{array}$ \\
\hline Educação em Saúde Bucal & $\begin{array}{l}\text { Dizem ser necessário ofertar } \\
\text { informações e outras atividades } \\
\text { educacionais que possibilitem a } \\
\text { aquisição de hábitos saudáveis para a } \\
\text { prevenção de doenças bucais, evitando } \\
\text { danos e outros riscos à saúde. }\end{array}$ \\
\hline Procedimento Clínico Odontológico & $\begin{array}{l}\text { Realizam exame da cavidade bucal da } \\
\text { criança, avaliação dos dentes e dos } \\
\text { tecidos dos moles e procedimentos } \\
\text { restauradores, quando necessários. }\end{array}$ \\
\hline
\end{tabular}

Fonte: Dados da pesquisa. 2019.

$\mathrm{Na}$ subcategoria 'procedimento clínico odontológico' foram incluídas as afirmações relativas ao exame da cavidade oral, a cronologia da erupção dos dentes decíduos, a avaliação dos dentes e tecidos moles, os procedimentos do tipo restauradores e a frenectomia/frenotomia lingual quando indicada. $O$ 'teste da linguinha', apesar de ser considerado um procedimento clinico, foi nominado como ubcategoria por tratar-se de um exame específico. Destaca-se que esse exame também ealizado por outros profissionais: médicos pediatras, enfermeiros e fonoaudiólogos.

A realização do teste da linguinha tem sua importância reconhecida pelo MS, recomenda um protocolo próprio para sua realização. A lei brasileira $\mathrm{n}^{\mathrm{o}}$ 
13.002/2014, determina a obrigatoriedade da aplicação do protocolo de avaliação do frênulo da língua em bebês (teste da linguinha) em todos os recém-nascidos no país. Essa avaliação inicial permite diagnosticar os casos mais graves, indicando a frenotomia ainda na maternidade. Nos casos duvidosos ou que não é possível a visualização do frênulo, uma nova avaliação deverá ser feita aos 30 dias de vida ${ }^{21}$.

A realização desse teste pelos dentistas entrevistados, durante as consultas de crescimento e desenvolvimento, ratifica a importância da presença desse profissional na $\mathrm{AB}$ e do trabalho desenvolvido por estes, visto que os prejuízos da anquiloglossia, não tratada nem diagnosticada precocemente, têm potencial para repercutir negativamente sobre a amamentação, incidindo em dificuldades na fonação, mastigação e até mesmo no estado emocional e interação social.

A subcategoria 'educação em saúde bucal' se sobressaiu em relação às demais. Nela estão contidas ações como: orientações à higiene bucal, controle da dieta com açúcar, incentivo e benefícios da amamentação exclusiva, conduta pós-traumatismo dento-alveolar, manobra de desengasgo, alimentação saudável, uso de chupetas e bicos de mamadeiras, mordedores, importância dos dentes decíduos, hábitos bucais deletérios, primeira dentição e entrega de insumos para higiene bucal.

Esses achados estão consonantes com as afirmações de Araújo et al ${ }^{3}$, no que diz respeito aos programas estruturados da $\mathrm{AB}$, exibindo como metas principais a promoção da saúde, a prevenção de doenças, o tratamento e reabilitação, requerendo, entretanto, a participação efetiva de profissionais, indivíduos (no caso, crianças e seus responsáveis) e sociedade.

Nessa linha de compreensão, o estudo de Macambira, Chaves e Costa ${ }^{6}$ mostram resultados satisfatórios em um grupo de crianças que recebeu educação em saúde bucal, ocorrendo maior adesão à escovação dentária, maior frequência diária de escovação, maior quantidade de crianças com realização de primeira consulta ao dentista, menor consumo diário de açúcar e doces e maior consumo de verduras e suco em açúcar. Esse resultado pode ser atribuído ao maior empoderamento dos is/responsáveis com adesão a hábitos saudáveis, trazendo reflexos consideráveis re a saúde bucal de seus filhos. 
Todos os participantes, excetuando-se um, veem as consultas de CD como uma ferramenta estratégica para se promover o cuidado de forma interprofissional e consideram um momento singular para interagir, dialogar e facilitar o empoderamento de pais e responsáveis, por meio da socialização de conhecimentos.

Acho extremamente importante, pois permite que eu atue de forma interdisciplinar enfatizando a promoção da saúde bucal do infante em parceria com os pais. A prevenção das doenças bucais é relevante, pois a cárie na dentição decídua é preditor de risco para cárie na futura dentição permanente (D-5).

Enfim, a participação interprofissional, por meio do trabalho em equipe tem se mostrado potencializadora das ações promotoras de saúde bucal durante as consultas de $C D$, evitando o desenvolvimento da cárie dentária e das doenças gengivais, ou seja, favorecendo que as crianças apresentem bocas mais saudáveis do que aquelas que não participam dessas consultas no território da $\mathrm{AB}^{14}$.

A análise do material coletado indica que as consultas de $\mathrm{CD}$ fazem parte do leque de atividades ofertadas nas USF do município de Caicó/RN, apesar de alguns dentistas entrevistados desconhecerem a realização de tal procedimento em suas UBS. Por meio da observação in loco, verificou-se que todas as UBS do município ofertam consultas de CD de forma sistematizada, sugerindo haver distanciamento destes profissionais que relatam desconhecimento quanto às ações cotidianas realizadas na USF.

Observou-se que três categorias profissionais se destacaram na participação das consultas de CD: enfermeiro, dentista e médico. Quando os profissionais de uma equipe, com especificidades variadas, passam a intervir sobre o processo de saúde da criança de maneira complementar e articulada, são asseguradas consultas qualificadas e eficientes, impactando sobre a saúde destas, ou seja, imprimindo um novo formato sobre o saber-fazer e novos cenários dentro da UBS ${ }^{22}$. Pode-se dizer que há uma zoável participação dos dentistas nas consultas de CD. Verificou-se que 34\% lizam consultas semanais, $22 \%$ a fazem mensalmente, e $22 \%$ esporadicamente. 
Quando perguntados sobre a autoconfiança durante as consultas de CD, a maioria respondeu que tinha segurança para participar do processo. Já aqueles que não demonstraram autoconfiança para desenvolver tal procedimento, fizeram referência a necessidade de oferta de educação permanente para qualificação e melhor domínio sobre o processo interprofissional acerca do CD.

Sugere-se aí uma lacuna no serviço ou um descompasso da gestão municipal com a Política Nacional de Educação Permanente em Saúde (PNEPS), uma vez que a PNEPS se apresenta como estratégia para a formação e desenvolvimento de trabalhadores do setor. Essa política orienta que os municípios se responsabilizem pela Educação Permanente em Saúde (EPS), devendo formular e promover a gestão da EPS e de processos relativos à mesma, orientados pela integralidade da atenção à saúde, criando, quando necessário, estruturas de coordenação e de execução da política de formação e desenvolvimento e garantindo seu financiamento ${ }^{23}$.

Foi possível captar que as ESB realizam o pré-natal odontológico ofertando diversas atividades às gestantes no tocante as ações de prevenção e de promoção e de assistência odontológica. Pittner, Bonassina e Pittner ${ }^{23}$ afirmam que para alcançar bons hábitos e garantir a saúde bucal desde os primeiros anos de vida da criança, faz-se necessário, além do acompanhamento gestacional, ofertar ações educativas e preventivas às gestantes, contribuindo para o empoderamento e consequentemente para a saúde bucal materno infantil.

Indagados se tinham conhecimento se outros profissionais realizavam orientações acerca de saúde bucal para os bebês, a maioria dos participantes reconheceu que outros profissionais orientam as mães sobre essa temática. Nessa direção, boa parte dos dentistas sentiu-se confortável com outros profissionais educando para a saúde bucal junto às mães e responsáveis pelas crianças. Contudo, houve quem demonstrasse preocupação com tal prática, justificando não fazer parte escopo de atribuições de outras categorias profissionais, o que poderia gerar istorções e orientações inapropriadas. Entretanto, Araújo et $\mathrm{al}^{3}$, defendem a mportância e a necessidade de se discutir como cada profissão pode colaborar com a moção da saúde bucal dentro das suas expertises nas consultas de CD, 
potencializando assim os efeitos positivos aos indivíduos e comunidade no tocante à integralidade do cuidado.

Portanto, faz-se necessário que a equipe de saúde estimule a participação dos sujeitos para a construção de autonomia: sujeito que fala, que faz críticas e que também tem desejos. Enfim, práticas que considerem valores, crenças, cultura apresentam-se como um novo modo de fazer, prometendo mais resolutividade dos problemas e com maior potencial de envolvimento e colaboração da comunidade, família e indivíduo ${ }^{24}$.

Os dentistas em tela participam das consultas de CD em parceria com outros profissionais da equipe articulando-se de duas maneiras: o CD compartilhado e o CD coletivo. No CD compartilhado, há participação de enfermeiros, médicos e dentistas, dentro do espaço clínico de cada profissional, isto é, as crianças e os responsáveis são assistidos por cada profissional, individualmente. No CD coletivo, as ações são direcionadas ao público alvo de forma coletiva: crianças e responsáveis/cuidadores em um único espaço, onde todos os profissionais ouvem, debatem e compartilham as atividades que são socializadas com todos os sujeitos presentes promovendo a interação e a aprendizagem no processo. Como relatado anteriormente, é nesse formato onde se insere a maior parte dos dentistas do município.

O CD favorece o trabalho interprofissional e o diálogo interdisciplinar apresentando maior robustez nas UBS contempladas com a residência multiprofissional da UFRN e com o Núcleo Ampliado Saúde da Família e Atenção Básica (NASF-AB), tendo em vista o suporte do apoio matricial que impulsiona e dinamiza as ações e atividades desenvolvidas nos territórios.

Hoje em dia as perspectivas do trabalho em saúde são interprofissionais e é assim que a gente consegue ampliar a saúde bucal, nesses espaços (D-IX).

A atenção à saúde na ABS pressupõe a integração de diversas categorias rofissionais atuando em equipe, devidamente amparadas em saberes terdisciplinares e matriciadas pelos diferentes níveis de referência do SUS5 ${ }^{5}$. Algumas rmações mereceram destaque: 
Quando eu disse que vinha hoje aqui, para participar dessa entrevista, aí a enfermeira falou: Ah! Então na próxima semana você vai começar a fazer o $C D$ coletivo comigo (D-XI).

Depois que eu respondi o questionário da pesquisa comecei a observar que havia uma grande demanda de crianças na unidade de saúde, aí eu perguntei ao enfermeiro por que ele não convidava a mim e ao médico para participar do CD. E depois que eu questionei, ele começou a me convidar. Agora eu estou participando (D-IV).

Tais colocações suscitaram reflexões sobre a necessidade de haver maior articulação entre os profissionais da equipe, da ocorrência de reuniões sistemáticas para o planejamento das ações, de estudos de casos e compartilhamento das atividades, entre outras estratégias.

De modo geral, compreende-se que as consultas de CD se constituem em momentos impares, permitindo instrumentalizar os pais, vislumbrando a mudança de hábitos nocivos e contribuindo para a produção da saúde.

A gente dialoga com as mães, orienta para que elas consigam fazer a leitura da caderneta da criança. Facilita a aquisição de conhecimentos debatendo o que pode ser feito em todas as fases referentes a infância (DVIII).

Contudo, Souza et $\mathrm{al}^{25}$, encontraram, em sua pesquisa, que pais de crianças préescolares se mostraram desinteressados em acompanha-las ao dentista para a realização de tratamento odontológico e, também, para consultas preventivas, embora, tenham se mostrado conscientes de sua importância. Expõe-se, portanto, a necessidade de se intensificar as ações de educação por meio de estratégias metodológicas que estimulem e motivem os pais ou responsáveis acerca da importância da saúde bucal dessa clientela.

Inquiridos sobre qual seria o momento mais propicio para dar início às tividades de saúde bucal junto aos bebês, os entrevistados citaram três momentos: urante a consulta puerperal, no período gestacional e durante o planejamento niliar. É durante a consulta puerperal que se estabelece o primeiro contato da 
criança com o dentista, sendo momento fundamental para sensibilizar pais/responsáveis na efetivação dos primeiros cuidados, ainda que sem a presença de dentes ou de anormalidades. A gravidez e o planejamento familiar são momentos férteis para aceitação de novas informações. Nessa perspectiva a educação em saúde deve se dar continuamente, por meio de abordagens que introduzam os determinantes ambientais, socioeconômicos e culturais ${ }^{23}$.

Quando a mãe aprende a cuidar de sua saúde bucal, ela consegue orientar o filho (D-XII).

A consulta deve começar durante o planejamento familiar. Precisamos desconstruir a cultura de que cada gestação é um dente perdido (DVIII).

A caderneta de saúde da criança também foi apontada como importante instrumento nas consultas de CD. Nela são registradas informações que podem guiar as atividades para um crescimento e desenvolvimento saudáveis, uma vez que agrega informações da gravidez ao parto, puerpério, situação vacinal da criança bem como orientações sobre a saúde bucal destas, isto é, possibilitando a avaliação e acompanhamento do CD. Esse instrumento facilita a comunicação entre pais e profissionais e orientam às mães aceca da saúde da criança12.

Foi através das consultas do CD coletivo que eu percebi o quanto é rica a caderneta da criança. Eu não tinha noção que continha todas aquelas informações e orientações. A partir de então, estou solicitando que as mães também tragam a caderneta para mim (D-VII, 2019).

Os dentistas também discorreram sobre algumas dificuldades: o trabalho pouco colaborativo e a pouca integração entre os membros da ESF, apontando como lemento indutor a rotatividade profissional, potencializadora da desintegração e da redução do vínculo com a população; a pouca adesão da população às ações coletivas saúde, seja por resistência ao tratamento odontológico, pelo medo ou outros tivos subjacentes e, por fim, a ausência de educação permanente em saúde. 
Em contrapartida, como elemento facilitador foi apontado a presença dos profissionais que estão cumprindo residência na UBS, uma vez que compartilham das atividades de CD, injetando força, disposição e criatividade:

Uma coisa que eu acredito estar contribuindo bastante é a presença dos residentes. Chega a ser uma equipe bem diversificada na minha UBS; eu acho que isso facilitou o compartilhamento e a aprendizagem (DVII).

A exemplo disso, Araújo et al. ${ }^{5}$ conseguiram bons resultados com a inserção de profissionais de uma residência multiprofissional na ESF no município. Os autores sugerem que tal proposta possa ser adaptada e replicada por meio da inserção de profissionais do NASF, o que poderá aumentar a adesão da clientela às consultas de $\mathrm{CD}$, promovendo a saúde bucal de maneira interprofissional, de forma indissociável da saúde geral.

Outro aspecto facilitador registrado diz respeito ao desempenho dos agentes comunitários de saúde e de seu vínculo com a população:

A gente tem sucesso em muitas ações que realiza. Mas, isso se deve muito aos agentes de saúde que são atuantes na questão da educação em saúde. O vínculo dos profissionais com a população faz com que essas ações sejam mais efetivas (D-IX).

Para Assis et al.22, o vínculo entre à equipe saúde da família e as mães, e sua consolidação, permitem um acompanhamento contínuo à criança e suprem as necessidades que emergem no nível de complexidade da $\mathrm{AB}$.

O planejamento das ações em saúde também foi citado como uma ferramenta estratégica dentro das USF, possibilitando promover uma relação dialógica e interativa entre os profissionais e, consequentemente, maior sucesso das ações ofertadas a população. Destarte, reuniões das equipes, para esse fim, foram nsideradas exitosas, uma vez que oportunizaram os debates e as discussões de casos, compartilhamento de conhecimentos, a identificação dos nós críticos e as estratégias enfrentamento que podem culminar com o planejamento das ações por parte das uipes. 
Na unidade acontece muita coisa, então, se a gente não sentar para planejar, não funciona. No início havia muita resistência, mas hoje em dia a gente melhorou muito. Há muita caminhada pela frente. Mas, uma coisa importantíssima para o planejamento dessas ações são as reuniões da equipe (D-IX).

Ao final do estudo, um consolidado dos resultados foi socializado com gestores, coordenação de Saúde Bucal e cirurgiões-dentistas da rede municipal de saúde. Possibilitou-se um debate que resultou em pactuações para: a deflagração de um processo de educação permanente em saúde bucal; a utilização dos dados da pesquisa para subsidiar o planejamento das ações no CD; a elaboração de um protocolo de saúde bucal para nortear o acompanhamento do $C D$, de forma mais interprofissional; a criação de um fórum permanente de debates sobre a Saúde Bucal na ABS. Nessa direção, foi construído um cronograma com as atividades a serem desenvolvidas, constituindo grupos operativos e de mobilização/divulgação, definindo prazos e metas para a efetivação das atividades.

Na primeira oficina/encontro foram pactuados: curso de capacitação em Saúde Bucal na infância, enfatizando o acompanhamento do CD; capacitação em educação popular em saúde e metodologias ativas para processos educacionais; oficina de planejamento de ações interprofissionais com enfermeiros, médicos, dentistas e demais profissionais envolvidos no CD; construção de um protocolo/guia para padronização de atividades e condutas; elaboração de uma cartilha sobre saúde bucal para orientar pais e responsáveis sobre a saúde bucal das crianças e outros cuidados relativos a saúde durante a infância; reuniões sistemáticas através de rodas de conversa com usuários (mães, cuidadores) e profissionais envolvidos no CD para integração e reflexão, de forma participativa, sobre as propostas discutidas.

\section{onclusões}

A percepção dos dentistas acerca do CD se traduz no acompanhamento das nças para um crescimento saudável. De modo geral, compreendem que deve er orientação aos pais e/ou responsáveis acerca dos cuidados com a saúde bucal 
como meio essencial para manutenção da saúde das crianças requerendo, para tanto, a oferta de ações educativas que fomentem a compreensão acerca da promoção da saúde e da prevenção de doenças bucais.

Produzir mudanças no processo de trabalho em saúde significa dialogar com práticas e concepções vigentes, problematizando e confrontando os saberes estabelecidos com a realidade. Sugere-se a adoção de estratégias metodológicas ativas, através de processo de educação permanente, para incrementar a participação dos dentistas no $\mathrm{CD}$, inclusive, com a adoção de consultas interprofissionais instituintes, quando se propõem ações ampliadas em parceria com os coletivos de trabalho anteriormente limitados aos aspectos predominantemente biomédicos.

A saúde bucal começa a ser introduzida nas consultas de $C D$, podendo vir a se constituir como potencialidade para o alcance de atenção e assistência mais integral em saúde. Contudo, há muito que se percorrer para se alcançar e efetivar a integralidade do cuidado em saúde bucal. E, nesse cenário, é imprescindível a participação crítica e efetiva de gestores, trabalhadores e usuários dos serviços de saúde do SUS, além de estudos complementares sobre o tema.

\section{Referências}

1. Brasil. Ministério da Saúde. Portaria no 2.436 de 21 de setembro de 2017. Aprova a Política Nacional de Atenção Básica, estabelecendo a revisão de diretrizes para a organização da Atenção Básica, no âmbito do Sistema Único de Saúde (SUS). Brasília: Diário Oficial [da] República Federativa do Brasil; 2017.

2. Pedraza DF, Santos IS. Avaliação da vigilância do crescimento nas consultas de puericultura na Estratégia Saúde da Família em dois municípios do estado da Paraíba, Brasil. Epidemiol. Serv. Saúde. 2017; 26(4):847-855.

Araújo DC, Lucena EES, Tavares TRP, Araújo TB, Araújo CM, Costa BMB et al. romoção de saúde bucal nas consultas de crescimento e desenvolvimento na atenção rimária: um relato de colaboração interprofissional. Revista Ciência Plural. 2018; (2):87-101.

ucena DBA, Guedes ATA, Cruz TMAV, Santos NCCB, Collet N, Reichert APS et Primeira semana saúde integral do recém-nascido: aç̃os de enfermeiros da atégia Saúde da Família. Rev. Gaúcha Enferm. 2018; 39:e2017-0068. 
5. Brasil. Ministério da Saúde. Secretaria de Vigilância em Saúde. SB Brasil 2010: Pesquisa Nacional de Saúde Bucal: resultados principais. Brasília, DF: SVS; 2012.

6. Macambira DSC, Chaves ES, Costa EC. Conhecimento de pais/cuidadores sobre saúde bucal na infância. Revista Saúde e Pesquisa, Maringá. 2017; 10(3):463-472.

7. Castilho ARF, Barbosa TS, Mialhe FL, Rontani RMP. Influência do ambiente familiar sobre a saúde bucal de crianças: uma revisão sistemática. J. Pediatr. (Rio J.). 2013; 89(2):116-123.

8. Schwendler A, Faustino-Silva DD, Rocha CF. Saúde Bucal na Ação Programática da Criança: indicadores e metas de um Serviço de Atenção Primária à Saúde. Ciênc. saúde coletiva. 2017; 22(1):201-207.

9. Minayo MCS. Análise qualitativa: teoria, passos e fidedignidade. Ciênc. saúde coletiva. 2012; 17(3):621-626.

10. Bardin L. Análise de conteúdo. São Paulo: Edições 70; 2011.

11. Malaquias TSM, Gaíva MAM, Higarashi IH. Perceptions of the family members of children regarding well-child check-ups in the family health care strategy. Rev. Gaúcha Enferm. 2015; 36(1):62-68.

12. Monteschio CAC, Gaíva MAM, Moreira MDS. O enfermeiro frente ao desmame precoce na consulta de enfermagem à criança. Rev. Bras. Enferm. 2015; 68(5):869-875.

13. Gauterio DP, Irala DA, Cezar-Vaz MR. Puericultura em Enfermagem: perfil e principais problemas encontrados em crianças menores de um ano. Rev. bras. enferm. 2012; 65(3):508-513.

14. Brasil. Ministério da Saúde. Secretaria de Atenção à Saúde. Departamento de Atenção Básica. Saúde da criança: crescimento e desenvolvimento. Brasília: Ministério da Saúde; 2012.

15. Ferreira ACT, Pieszak GM, Rodrigues SO, Ebling S. Consulta de puericultura: desafios e perspectivas para o cuidado de enfermagem à criança e a família. Vivências: Revista Eletrônica de Extensão. 2015; 8(20):231-241.

16. Cangussu MCT, Passos JS, Cabral MBBS. Necessidades e problemas de saúde bucal no Brasil e tendências para as políticas de saúde. In: Chaves SCL. Política de Saúde Bucal no Brasil: teoria e prática. Salvador: EdUFBA; 2016. p.47-78.

Martins LO, Pinheiro RDPS, Arantes DC, Nascimento LS, Santos Júnior PB. sistência odontológica à gestante: percepção do cirurgião-dentista. RevPannazSaude. 2013; 4(4):11-18. 
18. Chaves SCL, Almeida AMFL, Reis CS, Rossi TRA, Barros SG. Política de Saúde Bucal no Brasil: as transformações no período 2015-2017. Saúde debate. 2018; 42(spe2):76-91.

19. Carnut L, Frazão MP, Moura Neto JG, Silva ALAS. Principais desafios do acolhimento na prática da atenção à saúde bucal: subsídios iniciais para uma crítica. Revista da ABENO. 2017; 17(4):46-62.

20. Brasil. Ministério da Saúde. Portaria $n^{0} 1.130$, de 2015. Institui a Política Nacional de Atenção Integral à Saúde da Criança (PNAISC) no âmbito do Sistema Único de Saúde (SUS). Brasília: Diário Oficial [da] República Federativa do Brasil; 2015.

21. Martinelli RLC, Marchesan IQ, Lauris JR et al. Validity and reliability of the neonatal tongue screening test. Rev. CEFAC. 2016. Nov-Dez; 18(6):1323-31.

22. Assis TJ, Souza NO, Chaves ANS, Silva EAL. Sistematização do acompanhamento do crescimento e desenvolvimento da criança: relato de experiência. Revista de Enfermagem UFPE (online). 2015; 9(5):8493-8498.

23. Pittner M, Bonassina M, Pittner E. Educação para a saúde bucal infantil: da gestação à idade pré-escolar. Revista UNINGÁ Review. 2018; 27(2):22-29.

24. Simon E, Jezine E, Vasconcelos EM, Ribeiro KSQS. Metodologias ativas de ensinoaprendizagem e educação popular: encontros e desencontros no contexto da formação dos profissionais de saúde. Interface (Botucatu). 2014; 18(Suppl2):1355-1364.

25. Souza ERL, Santos JFD, Oliveira Filho AA, Alves MASG. Conhecimento de pais e cuidadores sobre saúde bucal de crianças pré-escolares. Revista UFG. 2017; 17(20):8094. 